\title{
Arquitectura rural en la costa norte Túcume: continuidad y mestizaje
}

\section{Rosana Correa Álamo}

\section{Introducción}

Sabemos que las obras arquitectónicas de la época prehispánica, colonial y republicana, constituyen buena parte de nuestro patrimonio y dinamizan un turismo cultural en ascenso; sin embargo y desde siempre, el interés se ha concentrado exclusivamente en los grandes monumentos como Machu Picchu, Chan Chan, iglesias y casonas coloniales, dejando de lado la observación de esas otras obras que el artesano rural hizo y sigue haciendo en su arquitectura cotidiana. Sin embargo, ese desinterés no refleja necesariamente su importancia, pues estas obras sorprenden por su gran belleza y coherencia, así como por su adecuación al medio en que surgen.

La importancia de estas obras menores pero numerosas radica, por un lado, en que esta arquitectura viva, facilita el entendimiento de patrones constructivos utilizados en épocas pasadas; $y$, por el otro, muestra cómo la tradición estilística y tecnológica se ha venido transmitiendo de generación en generación.
Esta arquitectura sencilla se las ingenia para dar un buen uso a los materiales de la zona, como el barro, la madera, la piedra, la caña, las hojas de palma y muchas veces se puede observar patrones que son producto de un mestizaje de etnias en el pasado, lo cual nos ayuda también a entender hechos históricos.

Afortunadamente la actividad turística ha madurado, apreciándose una mayor sensibilidad y curiosidad hacia estas manifestaciones artísticas y tecnológicas.

Existe mucho interés por parte de los visitantes, orientado no sólo para obtener información sobre el tema, sino también para cobijarse en estos espacios construidos con tecnologías tradicionales, que finalmente están más cerca de la esencia humana. De apoyarse la continuidad de estas manifestaciones se lograría que los mismos constructores revaloricen su tradición arquitectónica y no sucumban ante la tecnología del ladrillo y concreto, en la utilización del así llamado "material noble". 
Para comprobar la hipótesis someramente delineada en esta introducción, tomaremos el caso de Túcume, al norte de Chiclayo, que puede constituir un buen ejemplo de lo expresado hasta aquí, pues es un pueblo con historia y grandes $e$ interesantes manifestaciones de continuidad cultural.

\section{El pueblo de Túcume}

Viajando hacia el norte de Chiclayo, camino a Motupe, vamos encontrando una serie de pueblos que se alinean a lo largo de la antigua Panamericana Norte con nombres derivados del idioma "Muchik"1 como Mochumi, Illimo, Pacora, Jayanca hasta llegar después de 30 kilómetros a Túcume.

Túcume tiene su actual ubicación colindante con la antigua Panamericana Norte, desde las décadas iniciales de este siglo; el antiguo pueblo fue inundado por las lluvias y se reubicó, quedando abandonado como un caserío llamado Túcume Viejo, con su antigua y destruida iglesia colonial. En este caserío vivió el famoso brujo del norte Santos Vera.

El pueblo actual está formado por un centro urbano alrededor del cual se ubican diversos caseríos y viviendas rurales; es atravesado por la antigua carretera Panamericana Norte. Tiene un trazado ortogonal de manzanas cuadradas con una plaza principal donde se ubica la iglesia de barro construida en la época republicana. Las fachadas de adobe de las casas están coronadas por cornisas en forma escalonada a manera de pirámides, bajo las cuales sobresalen los "cañones" o gárgolas sostenidas por pilastras molduradas en yeso de forma muy sencilla.

Los colores rosado y celeste son los predilectos, lo cual le da un aire festivo a algunas calles. Pero al lado de estas expresiones, también podemos ver en muchos casos las huellas de los desastres que provocaron las lluvias en

${ }^{1}$ Quechua Norteño tiempos del llamado Fenómeno de El Niño.

Si ingresamos a las casas urbanas de Túcume, podremos ver en algunos casos un pequeño patio de ingreso, que se usa como ambiente de distribución de la casa con respecto al exterior. De este patio nace un corredor lateral que recorre tangencialmente los ambientes internos de la casa y termina en un patio-corral grande que se comunica con la cocina que cuenta con un horno de barro para sus hornados.

Al interior los ambientes son frescos y aireados y de gran altura, mirando hacia arriba podemos ver las ventanas de madera tipo claraboya que sobresalen del techo y al mismo tiempo las vigas retorcidas de algarrobo recubiertas con barro, que amarran los gruesos muros de adobe de la casa.

Hay un hecho que llama mucho la atención a cualquier visitante: cuando el sol se oculta, algunos pobladores al retornar de sus labores agrícolas, ingresan con sus animales, como vacas, toros o caballos por la puerta estrecha de sus viviendas y los acomodan en el patio-corral del fondo, para asegurar que no sean robados por los abigeos. La plaza central, como en todo pueblo, es el punto de reunión nocturna de los vecinos. En una de sus esquinas se puede tomar un "champús"2.

En los alrededores de este centro urbano se desenvuelven los caseríos rurales entre campos de maíz, frijol y algarrobo, que tienen nombres particulares como "La Raya", "Nancolán", "El Horcón", "El Pavo", etc. Estos caseríos son regados por los ríos La Leche, Chancay y el gran Canal Taymi que se ramifican a través de acequias y canales menores que son limpiados cada cierto tiempo en faenas comunales para garantizar el fácil abastecimiento de agua a cada caserío. En el recorrido de los caminos podemos ver pequeños puentes de madera de algarrobo que posibilitan cruzar sobre estos canales e ingresar a las casas de los pobladores. Así mismo se observan ingresos

${ }^{2}$ Bebida espesa de maiz, chancaca y guanábana. 
con troncos tallados en esta misma madera.

\section{La arquitectura de los gentiles de Túcume}

Pero antes de continuar con el análisis de la arquitectura rural de los caseríos de Túcume, debemos remitirnos a las evidencias arquitectónicas y urbanísticas que la antecedieron en la época prehispánica y establecer en qué contexto histórico se consolidaron.

Los caseríos rurales de Túcume rodean a un gran cerro que corona todo el valle, llamado "El Purgatorio", en cuyas faldas descansan 26 edificios piramidales de barro, construidos consecutivamente por los hombres de las culturas Lambayeque, Chimú e Inca; hoy llamados "Gentiles" por el poblador rural.

De acuerdo a las investigaciones realizadas por Izumi Shimada desde 1985 a 1990 en Batán Grande y las financiadas por Thor Heyerdhal en Túcume, el Dr. Krzysztof Makowski señala que se ha podido definir que entre los siglos IX y XI d.C., Batán Grande se constituye en el principal centro político de la región, instaurándose el estilo Sicán. El poder de los gobernantes descansaba sobre la producción orfebre en gran escala y alto nivel tecnológico. En la capital Batán Grande se construyen grandes edificios piramidales de adobe con plataformas superpuestas y amplias plazas donde se localizan los entierros de la élite.

A fines del siglo $\mathrm{XI}$ d.C. las precipitaciones provocadas por el Fenómeno de El Niño, contribuyeron probablemente a la caída de los Señores de Batán Grande, abandonándose la capital y cesando la construcción monumental.

Mientras tanto Túcume adquiere el status de capital en el nuevo sistema político, modificándose algunos patrones arquitectónicos, la iconografía y la modalidad de enterramiento. Este conjunto urbano ocupó una extensión aproximada de 220 hectáreas.
Hasta el momento las investigaciones realizadas han dado prioridad al estudio de cada uno de los edificios, estudiando su arquitectura, patrones de enterramiento, piezas de contexto como cerámica, textilería, orfebrería. Quedando por definir los patrones de asentamiento del conjunto como: traza urbana, tendencias de usos de suelo, sistemas de abastecimiento del centro urbano, jerarquización de vías y sistemas de drenaje de aguas. (Foto 1)

\section{Foto 1}

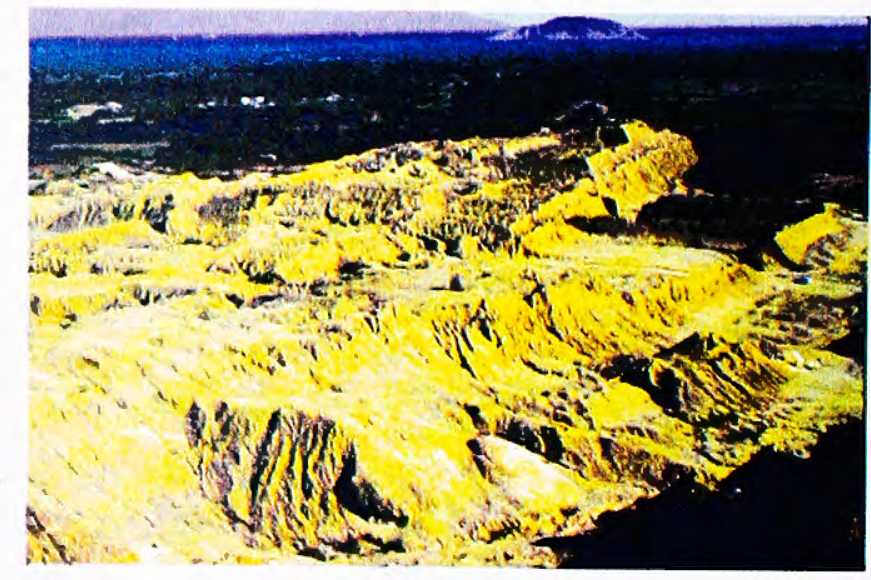

\section{Descripción arquitectónica y constructiva}

Si nosotros observáramos una pirámide en su interior, veríamos una serie de plataformas superpuestas construidas en diferentes tiempos y reinados, cada una de ellas con muros de adobe adosados.

En algunas evidencias encontradas por el Dr. Alfredo Narváez, estas plataformas tendrían refuerzos horizontales cada cierto tramo a manera de estructura tejida de algarrobo y caña que mantenía armado el conjunto.

El adobe utilizado para la construcción de los muros se elaboró inicialmente sin molde con la forma de un pan. Luego cuando éste secaba se asentaba con piedras pequeñas, barro y agua para construir los muros. Posteriormente en los 
muros de los edificios piramidales se utilizó el adobe, hecho en molde de caña con forma plana; este adobe presenta características de gran resistencia e impermeabilidad; está hecho con barro, caolín o sílice y agua.

Los adobes se apilaban tal como se puede ver en la actualidad; con juntas de barro, formando grandes muros trapezoidales, que cuando eran murallas alcanzaban alturas de aproximadamente ocho a diez metros, con espesores de dos a tres metros. (Ver Dibujo 1)

\section{Dibujo 1}

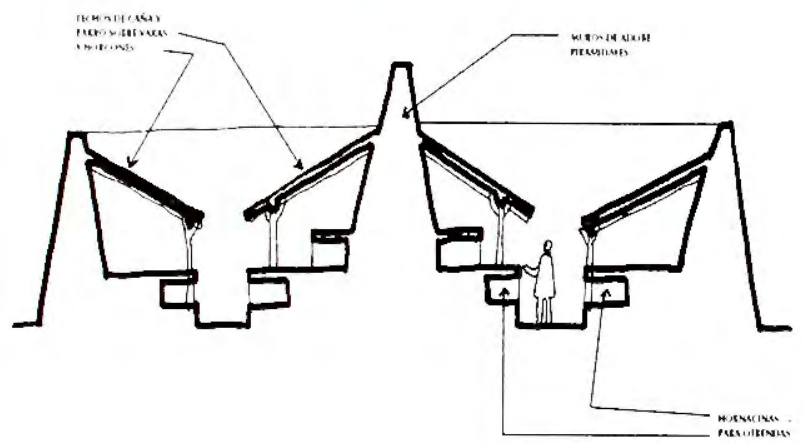

Sobre cada una de las plataformas se distribuían los recintos comunicados con los patios a través de sus corredores semitechados y rampas que daban a otros niveles. En algunos casos estos recintos contaban con amplias hornacinas o adoratorios de quincha $y$ adobe que miran hacia el valle.

La arquitectura de los recintos se define con gruesos muros trapezoidales, sobre los cuales descansan tarimas o "banquetas" de adobe que se cubrian con techos ligeros 0 densos, estructurados con madera de algarrobo, caña y barro; preocupándose porque sus pisos y paredes estén perfectamente protegidos con una fina capa de barro combinada con algunos minerales que le daban propiedades de impermeabilidad.

Algunos muros eran coronados con altos relieves con motivos de aves, peces, personajes navegando o danzando, muchas veces pintados en rojo, amarillo, negro y blanco con tierras de color o minerales.

En los edificios piramidales, se han dado diversos tiempos de ocupación, compartiéndose varios usos de suelo; así vemos en la gran pirámide Huaca Larga, evidencias de talleres de textilería con sus largos corredores semitechados y amplias hornacinas para almacenamiento, plazas y recintos ceremoniales finamente ornamentados con pintura mural.o altos relieves en sus muros, enterramientos de jefes y artesanos de jerarquía. Estos sectores quedaban comunicados por patios, plazuelas y rampas de mediano y gran tamaño.

Es importante tomar en cuenta las hipótesis y reflexiones que plantea el Dr. Cristóbal Campana (1994), a partir de los obras alfareras de los Mochicas que son los antecesores de los Lambayeque y Chimú. En sus ceramios sintetizan una edificación, como una sucesión de plataformas piramidales sobre las cuales instalan uno o dos recintos con techos en pendiente sostenidos por horcones de algarrobo y ventanas altas para una mejor ventilación. La ramada también aparece muchas veces representada y tal como lo manifiesta el Dr. Campana este ambiente semitechado al ingreso de la edificación permite una renovación de aire frío $y$ donde posiblemente en el día era donde realizaban sus tareas cotidianas por la frescura del espacio.

\section{El algarrobo}

Este árbol, especie nativa de la zona, fue utilizado como elemento estructural en la construcción de las plataformas y muros; habiéndose escogido al parecer por su gran resistencia a la humedad y a los factores climáticos.

El algarrobo tiene la característica de no requerir de mucho agua. Su raíz tiene la capacidad de llegar a grandes profundidades para tomar el agua subterránea y mientras más seco sea el suelo, éste alcanza mayores alturas. 
Desde épocas muy antiguas, después de cada Fenómeno de El Niño, las lluvias arrasaban con los campos de cultivo y los montes de algarrobo recuperaban nuevamente áreas que habían sido trabajadas por el hombre. En este proceso este árbol ha podido sobrevivir hasta hoy, gracias a las fuertes lluvias de cada 10 años, que además aceleraban su crecimiento.

Este árbol tiene un fruto llamado "algarroba" de gran valor nutritivo y que en épocas prehispánicas era base en la alimentación de los niños a través de mazamorras, chupes y la famosa "algarrobina" que es una miel oscura que se obtenía después de hervirla en "cayanas" (fuentes de barro).

Actualmente se sigue elaborando este producto y el hombre de campo lo consume abundantemente para garantizar su fortaleza y longevidad; asimismo la algarroba es alimento de los animales preferentemente del ganado caprino.

En las construcciones, se le ha encontrado en los edificios piramidales como columna, viga o formando un entramado para sostener o amarrar muros y plataformas de adobe o bien estructurando techos de hornacinas y corredores aireados como en Huaca Larga, Huaca Uno, entre otras.

Además de su uso constructivo, también fue materia prima para la elaboración de instrumentos de trabajo artesanal como ruecas ${ }^{3}$ para hilar, bastones para telar; instrumentos de cocina como batanes4; mobiliario como mesas, bancas, entre otros implementos.

Por otro lado, gracias a las evidencias halladas en los edificios de uso ceremonial, se puede deducir que este árbol tuvo un carácter sagrado. Se han encontrado algarrobos con motivos zoomorfos y antropomorfos, tallados en sus curvaturas, a manera de ídolos al igual que

\footnotetext{
${ }^{3}$ Pequeños bastones de madera, que se giraban rápidamente para hilar el algodón o lana.

${ }^{4}$ Especie de pequeñas bateas de algarrobo, donde se muele granos y otros vegetales con una piedra.
}

los "Chachapoyas" 5, apareciendo en áreas de posible carácter ceremonial.

\section{Un templo "El adoratorio"}

Este recinto tiene al interior aproximadamente cinco metros por lado y hasta el momento, es el único que no se encuentra sobre un edificio piramidal, está construido con muros de adobe y columnas de algarrobo y posiblemente tuvo una cornisa exterior que coronaba el recinto como en los ceramios arquitectónicos de la cultura Lambayeque.

El grupo de investigación le ha dado el nombre de "adoratorio" porque contiene gran cantidad de ofrendas, réplicas miniaturizadas de objetos ceremoniales y pequeños ídolos de plata que parecen representar a jefes por el tipo de ornamentos que llevan. Estas ofrendas se encuentran en hornacinas o esparcidas sobre dos amplias tarimas de barro que rodean a una enorme piedra empotrada en el suelo e inclinada hacia el norte y al ingreso.

Sobre las tarimas sobresalen dos hileras de columnas de algarrobo cubiertas de caña y barro que por su número parece que cumplen un carácter sagrado y no estructural. ( Ver Dibujo 2)

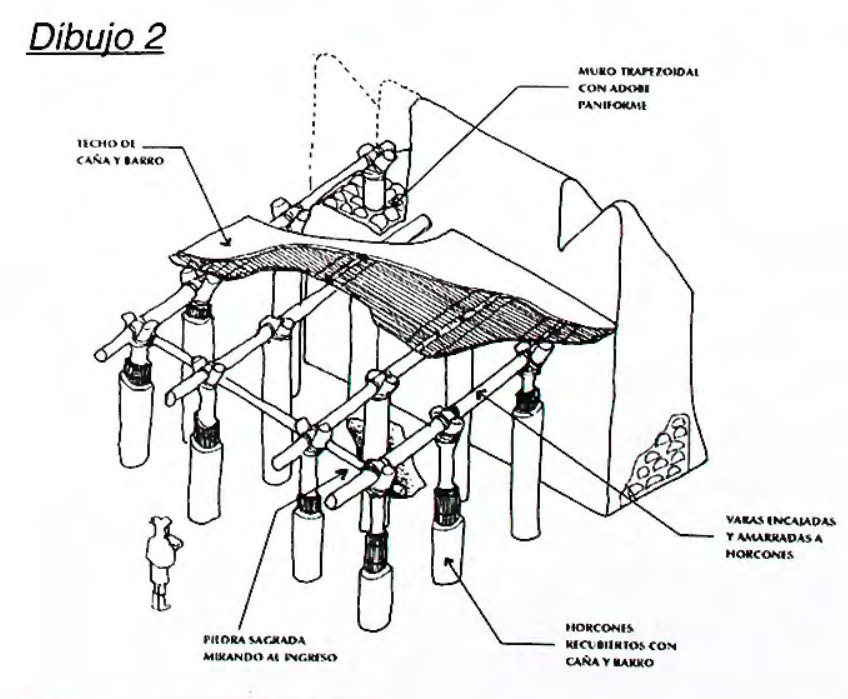

${ }^{5}$ Cultura que se afinco en los andes amazónicos del norte en los 600 años d.C. aproximadamente y fue conquistada por los Incas. 
El ingreso que mira al norte está definido por dos algarrobos y nos lleva hacia una plaza ceremonial rodeada de "banquetas" o tarimas de adobe; donde además hay restos de entierros de llamas. Parece ser que a este adoratorio sólo ingresaban los personajes de jerarquía y no el pueblo. (Ver Dibujo 3)

\section{Dibujo 3}

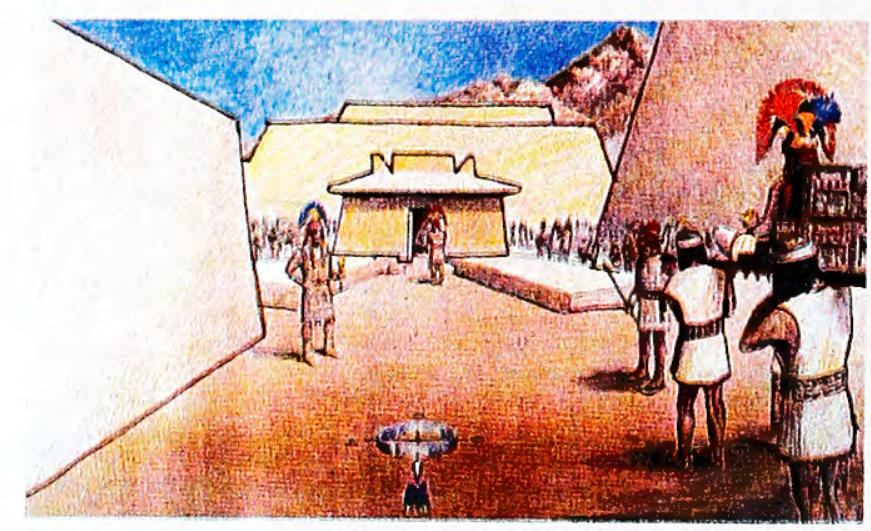

Hasta hace unos ocho años, antes de los trabajos de excavación, éste era el sitio preferido por brujos y curanderos del lugar y alrededores, para practicar sus sesiones y ritos ceremoniales. Actualmente lo practican clandestinamente, burlando a veces la vigilancia de los guardianes, de la misma forma que lo hacen los huaqueros en Semana Santa, porque es una costumbre ancestral el profanar las huacas precisamente en esta fecha cristiana, lo cual viene de la época colonial en el proceso de extirpación de idolatrías.

\section{Los ritos ceremoniales y la arquitectura temporal}

También se puede ver en las evidencias encontradas que se instalaron recintos de carácter temporal en las grandes plazas entre pirámides, cuando se efectuaban los grandes eventos ceremoniales, para los pobladores de otros señoríos, que venían a rendir culto y tributo al señor $y$ jefe. $Y$ para ello se requería de delgados algarrobos que sostuvieran ligeros techos de caña y totora y muros de quincha, lo cual es fácil y rápido de construir y desmontar. En los ceramios mochicas se han representado estas construcciones ligeras para efectuar las labores artesanales, de esta misma manera parecen haber sido las construcciones temporales. (Ver Dibujo 4)

\section{Dibujo 4}

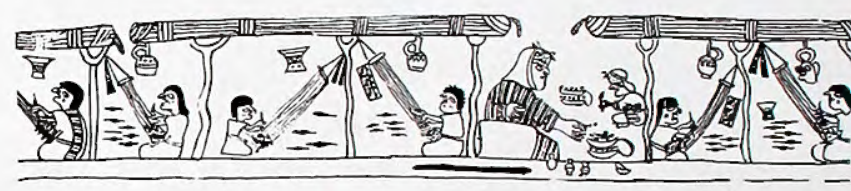

Al lado de Huaca Larga, una de las más importantes del conjunto urbano, existe una gran plaza amurallada de aproximadamente 100 metro de largo por 60 de ancho y los muros tienen una altura de ocho metros. Este parece ser uno de los lugares de estancia temporal para estas viviendas desmontables; es interesante apreciar las condiciones acústicas y de confort que tiene el lugar para controlar las altas temperaturas y los fuertes vientos en las tardes.

\section{La arquitectura rural del Túcume vivo}

En esta descripción apretada de la arquitectura prehispánica del complejo arqueológico Túcume, se ha dado prioridad a los elementos y patrones arquitectónicos que se encuentran en la arquitectura rural de hoy, proporcionándonos el nivel de permanencia cultural. Sin olvidar que nuestros pueblos han recibido honda influencia constructiva por parte de los españoles que, a su vez, nos traían la tradición constructiva de las culturas orientales.

\section{Templos de barro y algarrobo}

En el transcurso de las investigaciones, el Dr. Narváez planteó la hipótesis de un posible incendio de las huacas y edificios piramidales de Túcume y esto lo sustenta en sus hallazgos de muros de adobe cocido. Este hecho puede haber 
sido ejecutado por los descendientes de la cultura vencida, para que sus adoratorios no fueran profanados por los españoles o bien por los evangelizadores para eliminar a los espíritus diabólicos de los dioses antiguos.

En este contexto nosotros vemos en Túcume que los cultos y devociones se han dividido entre ritos cristianos y ritos de las épocas de los Gentiles6.

Actualmente es conocido Túcume y sus alrededores por la existencia de gran cantidad de brujos y curanderos, que en sus mesas de trabajo $y$ peticiones tienen a sus ídolos cristianos $y$ prehispánicos, evocando al Cerro Purgatorio a la vez que a la Virgen de la Natividad. (Foto 2)

\section{Foto 2}

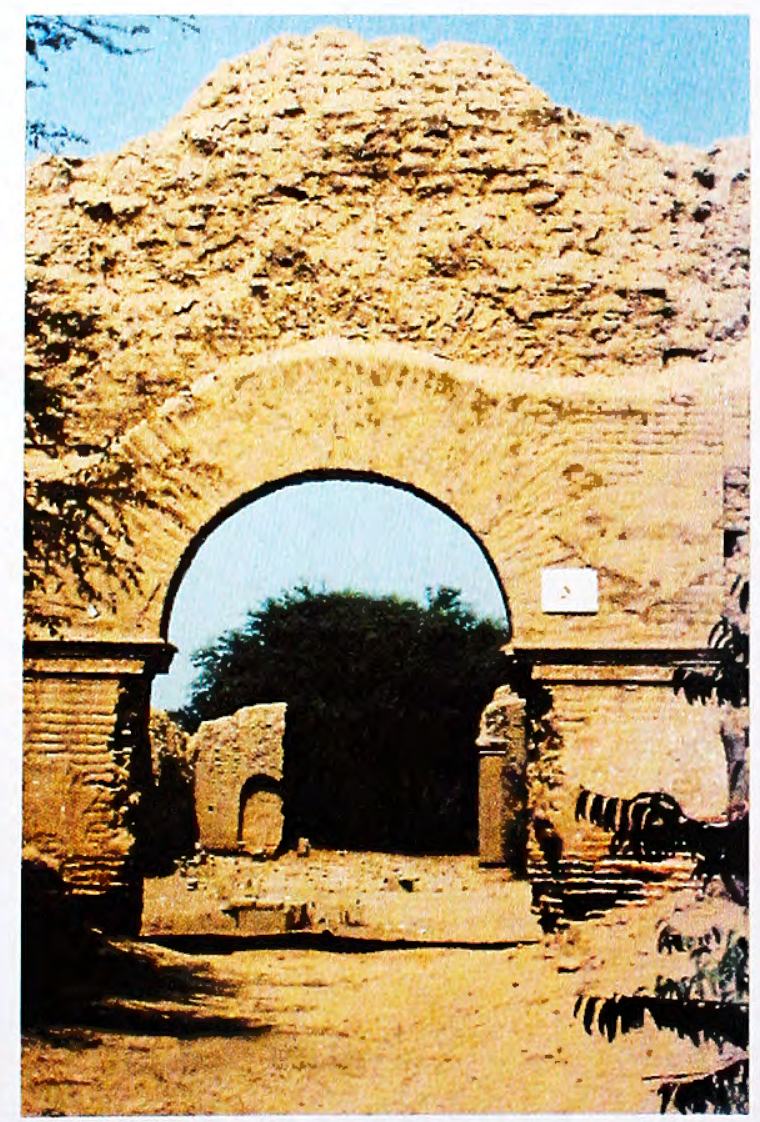

De esta misma manera, vemos una arquitectura religiosa rural que alberga en forma muy natural íconos religiosos de los dos cultos, por un lado altares de adobe en forma piramidal que contienen a una gran cruz de algarrobo ornamentada con réplicas miniaturizadas de objetos deseados, tal como en las ofrendas del Adoratorio y rodeada por hornacinas con santos o imágenes cristianas. En otros casos pueden verse altares que reproducen en barro los pomposos retablos de las iglesias coloniales con vírgenes como la Inmaculada Concepción o la Natividad, protegidas por alguna pequeña cruz de algarrobo.

Estas capillas son construidas con muros de adobe, techos con varas retorcidas de algarrobo, encarrizado de caña y una torta de barro en la cobertura.

El recinto religioso de aproximadamente cuarenta metros cuadrados, está coronado por un altar de barro, hecho artesanalmente con las formas que se mencionó anteriormente y en sus muros laterales se apoyan unas tarimas de adobe que sirven de descanso a los devotos.

Estos templos no tienen bancas en el centro del recinto lo cual nos hace recordar al uso prehispánico de las banquetas laterales en las plazas ceremoniales donde permanecía el pueblo, porque al templo no ingresaban.

Esta tipología se repite en tamaños reducidos a manera de maquetas para rendir culto a un muerto, a un santo o a una pequeña cruz ubicándose en el recorrido de un camino o sobre alguna pirámide de los Gentiles ${ }^{6}$.

\section{Ornamentos temporales en días de culto}

En los días patronales de una virgen o un santo, la iglesia de barro es galardonada con varios pórticos hechos de caña y adornados con muchas frutas coloridas como naranjas, plátanos, guanábanas; lo cual sucede en diversos lugares del norte como el pueblo de Moche ${ }^{7}$, geniales

\footnotetext{
${ }^{6}$ Los pobladores denominan así a los hombres prehispánicos que viven en las huacas.

${ }^{7}$ Arkinka23-Antonio Benavides 1997.
} 
ejemplos de que colinda con las huacas de EI Sol y de La Luna, arquitectura Mochica. (Foto 3)

\section{Foto 3}

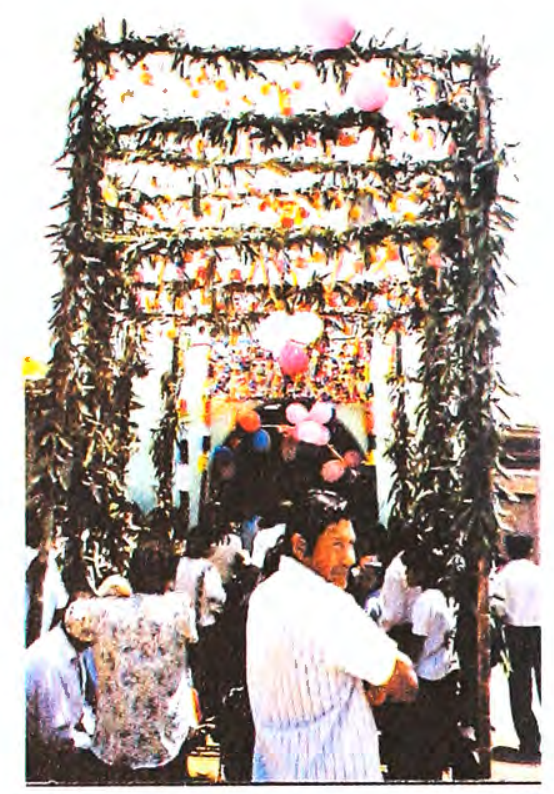

Es realmente particular ver las procesiones nocturnas por los caminos rurales, siguiendo a las imágenes, como la Virgen de la Natividad, la Inmaculada Concepción, Virgen del Carmen, en algunos casos acompañadas por "Los Diablicos" que danzan al compás de la "Chirimilla"8 y un tambor, declarándose vencidos ante su magnificencia.

\section{Casas de barro y quincha}

La concepción que tiene el poblador rural sobre la vivienda es que debe ser temporal. Ellos están conscientes que viven en una zona de constantes desastres ocasionados por el Fenómeno de El Niño y no construyen una casa fuerte para que soporte las inundaciones sino una casa que sea fácil de reconstruir. Y para ello es que la construyen en quincha, tal como lo hacían los Gentiles, al lado de las pirámides, para uso temporal durante los días de ritos ceremoniales e intercambio entre Señoríos y pueblos.

\footnotetext{
${ }^{8}$ Instrumento de viento con un sonido muy agudo, traf́do por los españoles.
}

La quincha, que es un tejido de caña a manera de cesta, con recubrimiento de barro trabajado, es fácil de tejer para el poblador que la fabrica con caña brava cortada en mañanas de luna menguante, entretejida con amarres de junco.

Coincidentemente esta forma de construir también la conocían los españoles a través de su contacto con los árabes, pero con estructura de madera. Esto facilitó su permanencia y continuidad como sistema constructivo tradicional en zonas de valle costero, donde la caña bambú y caña brava crecen con facilidad y en forma natural.

En las casas más antiguas se pueden ver todavía, muros con doble quincha y barro de relleno al centro, lo cual es doblemente resistente y térmico. Hoy ya no se construye así porque se requiere mayor cantidad de material y más trabajo.

Estos muros de quincha son sostenidos y amarrados por fuertes horcones de algarrobo que se incrustan en el subsuelo y con sus horquetas con forma de " $Y$ ", sostienen las varas o vigas. Al igual que en las capillas y en las pirámides prehispánicas, esta estructura de algarrobo es cubierta con caña y barro trabajado. Los techos poseen muy poca pendiente y no tienen ningún material que los impermeabilice. (Ver Dibujo 5)

\section{Dibujo 5}

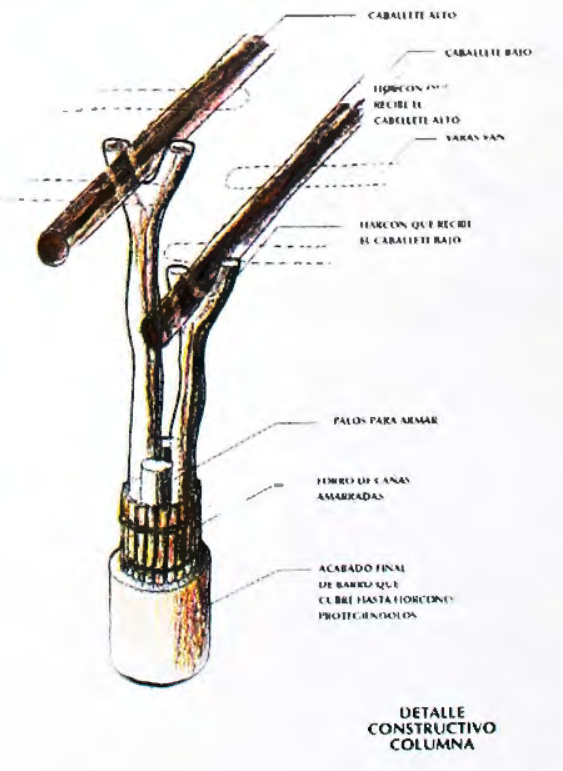

Turismo y Patrimonio, Año1 
En los momentos de emergencia por inundaciones, los muros de quincha caen pero quedan los troncos de algarrobo que tienen gran resistencia a la humedad y por lo tanto solamente se reconstruyen los muros de quincha que se sostienen entre algarrobo y algarrobo.

Esta tipología de vivienda nos remite a las casas de pueblo de las épocas prehispánicas, que se diferenciaban del carácter de permanencia que sí tenían los edificios piramidales. Pero, sin embargo, sí se toman algunos patrones que hemos visto anteriormente.(Foto 4 )

\section{Foto 4}

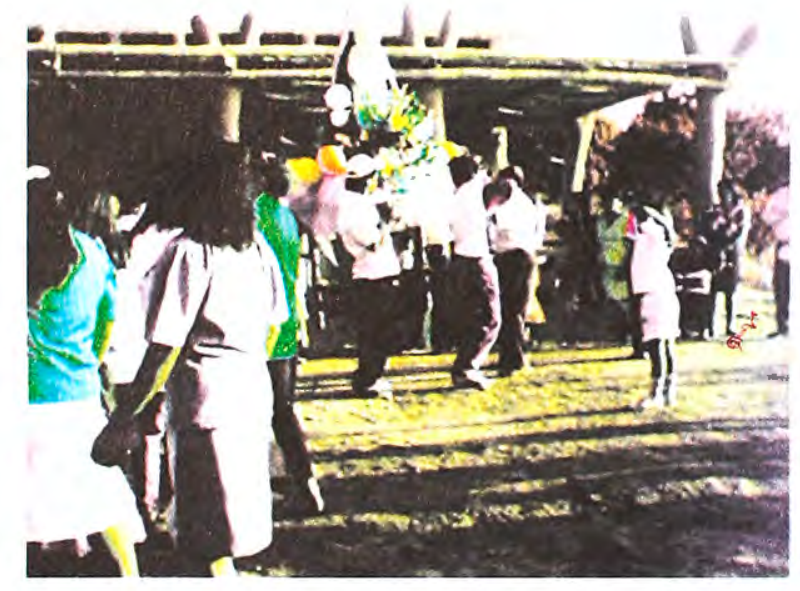

\section{Las casas de adobe}

En el sector rural existen también casas de adobe, pero en menor proporción que en el pueblo donde abundan.

El adobe que se utiliza se elabora en moldes de madera, mezclando barro, agua y cáscara de arroz; con este adobe se construye los muros que ya no son trapezoidales como en la época de los Gentiles, sino rectos debido a la herencia colonial. En algunos casos las viviendas son de más de un piso pero, generalmente, por la calidad pobre del adobe, se construyen casas de uno; los muros, mayormente no cuentan con cimentación de piedra y barro como en la sierra, colocándose solamente dos hiladas bajo el nivel del suelo, tal vez confiados en que no llueva todos los años.

\section{Distribución arquitectónica de una casa rural en Túcume}

De las épocas prehispánicas no hay evidencias de cómo vivía el pueblo, pero sí han sobrevivido las viviendas de los gobernantes, donde se utilizan banquetas de adobe y muebles fijos hechos con el mismo material.

La vivienda del poblador rural de Túcume se puede distinguir a distancia por la presencia de los algarrobos retorcidos que sostienen la casa, aunque si la analizamos encontramos los siguientes ambientes:

a.- La Ramada: espacio sombreado definido por horcones de algarrobo y entramado de caña que en muy pocos casos tiene muros altos, generalmente tiene un muro bajo; su mobiliario son las tarimas de adobe o bancas de algarrobo que rodean a una mesa de esta misma madera para ofrecer a los vecinos o invitados un piqueo y una rica chicha de jora; esta ramada la podemos ver representada en los huacos arquitectónicos de la cultura Mochica, donde muchas veces hay un personaje sentado. En la arquitectura rural de la Sierra también aparece este espacio con el nombre de "Masma" y cumple la misma función. (ver Dibujo 6) (ver Dibujo 6a)

\section{Dibujo 6}

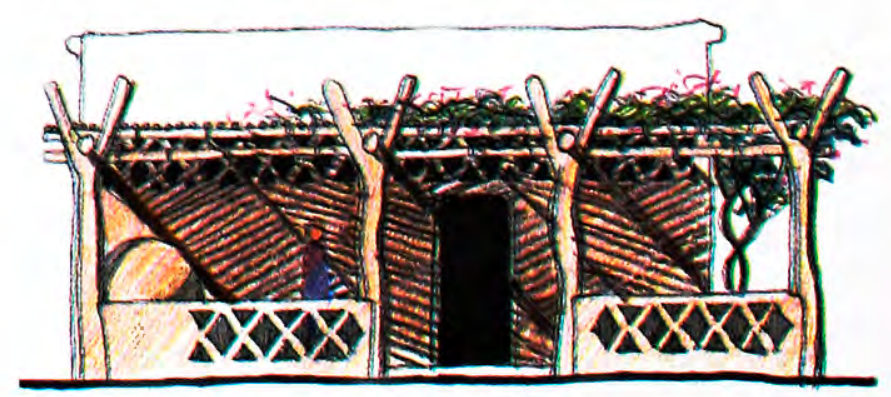




\section{Dibujo 6 a}

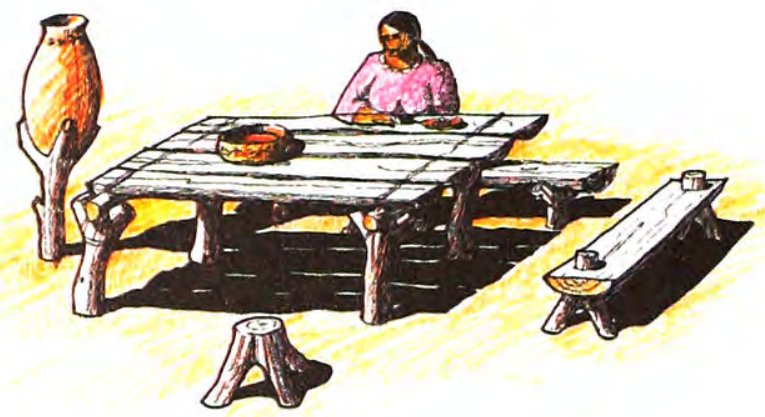

b.- La Sala: pasando esta ramada nos encontramos con un gran ambiente que tiene en una de sus paredes una hornacina para adorar a un santo o a la Cruz de Chalpón. Aquí se celebran las fiestas de cumpleaños y las de mayordomía.

c.- La Cocina: que tiene un techo más bajo, con un mobiliario culinario como el fogón con varias hornillas para colocar las ollas de barro; los "tabancos" que son mesas de caña con amarres de junco, para el preparado de los alimentos; el "batán" que es un tronco de algarrobo tallado en forma de batea, sobre el cual se mece una piedra para moler los ajíes o el maíz para la chicha.

Al lado del fogón se encuentra un pequeño corral para cuyes y aves menores.

d.- Detrás de la sala, donde también se come, se encuentran los dormitorios a los que llaman cuartos y éstos se conectan unos con otros a través de puertas continuas. Cerca al corral de animales mayores se encuentra el dormitorio del jefe de familia o hermano mayor que es quien hace guardia toda la noche con escopeta en mano.

e.- Los servicios higiénicos están constituidos por una letrina, que se ubica en el patio posterior o corral de la vivienda.

\section{Casa de un brujo}

dedica a las labores agrícolas y a la vez practica la brujería y el curanderismo, para lo cual él recibe a sus pacientes los días viernes o sábados a partir de las nueve de la noche y amanecen hasta las cinco de la mañana del siguiente día.

La casa es como la de cualquier poblador, pero posee un patio más grande de lo normal, para realizar sus mesas de trabajo y recibir a sus pacientes, este patio esta rodeado de cruces de algarrobo que tienen cierto valor sagrado y son veneradas en la fiesta de la Cruz de Chalpón. Colinda con este espacio un corral diferenciado para criar a los cuyes que van a ser sacrificados en sus curaciones; al oeste se ubica un cuarto donde el brujo guarda celosamente sus instrumentos $y$ ofrendas $y$ al lado un pequeño ambiente donde prepara sus brebajes en un fogón de barro, como la bebida del cactus San Pedro (alucinógeno).

Los días viernes el brujo prepara su "mesa de trabajo" (del bien) ubicada exactamente al sur del patio, mirando al Cerro Purgatorio; en esta mesa coloca a la izquierda objetos encontrados en las huacas y en el lado derecho esculturas e imágenes cristianas, esta mesa es rodeada de sables y espadas de madera y metal, las cuales son usadas por los pacientes y el brujo durante la sesión para vencer al mal.

Frente a esta mesa de trabajo se encuentra "la mesa del mal", rodeada también de sables pero sin íconos, aquí un personaje llamado "el alzador" ayuda al paciente a eliminar el mal haciéndolo ingerir por la nariz tabaco con alcohol, depositados en una concha de mar, y luego de danzar con los sables en el lado este, el paciente ingiere la bebida de San Pedro, conjuntamente con el curandero, y evocan a los cerros, a las huacas, a las lagunas de Las Huaringas, a la Cruz de Chalpón, a la Virgen de la Natividad, a San Martín de Porres, entre otras representaciones. (Ver Dibujo 7) 


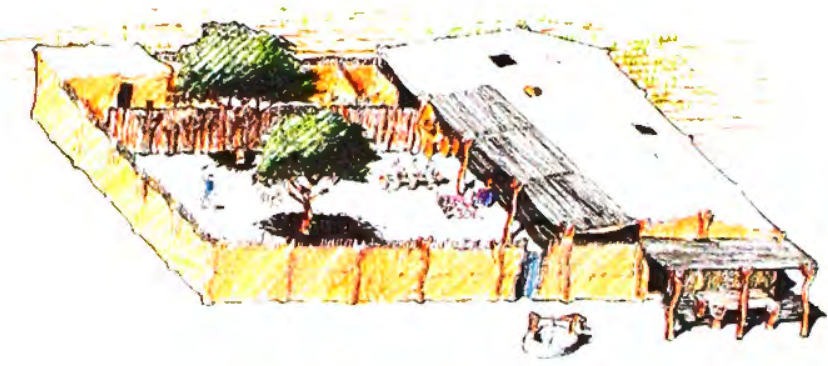

En esta misma vivienda, en la sala principal de la casa ubicada al sur se encuentra una gran urna de vidrio donde permanece una hermosa imagen colonial de la Virgen de la Natividad, que se le rinde culto en el mes de setiembre y fue rescatada de una gran inundación que sufrió la antigua iglesia de Túcume.

El curandero mencionado es quien guarda esta Virgen y la venera de la misma forma que venera a los dioses de los Gentiles.

\section{Buscando el agua como los algarrobos}

Como en las épocas prehispánicas, en la actualidad se sigue cavando la tierra a gran profundidad para conseguir agua del subsuelo, siendo el material de contención solamente el barro endurecido. En algunas viviendas sobreviven "norias" muy antiguas cuyos muros han sido consolidados con troncos de algarrobo hasta el subsuelo. $Y$ en la parte superior, tienen una gran manivela con horquetas del mismo árbol, para subir el agua en recipientes de madera o fierro.

Estas perforaciones se hacen artesanalmente con el trabajo de ayuda mutua, lo cual toma aproximadamente dos semanas.

\section{Reflexiones finales}

El poblador rural de Túcume es sumamente tradicional y respetuoso de sus ancestros y cultos sean estos cristianos y/o prehispánicos, lo que puede constatarse en cualquier reunión de amigos, fiesta patronal, faenas agrícolas, etc. Como constructor $y$ arquitecto solamente ha tomado los patrones técnicos de las épocas prehispánica y colonial, que le permiten hacer una arquitectura temporal de algarrobo y quincha, para enfrentar desastres provocados por las lluvias que suceden cada 10 años, tal y como lo hemos visto anteriormente.

El repetir estas maneras ancestrales no les ha permitido experimentar, medir y consolidar su tecnología como lo hicieron las culturas pasadas frente al mismo fenómeno y más bien, ésta se ha ido degradando generacionalmente. Desde nuestra práctica arquitectónica y constructiva, hemos visto los siguientes problemas:

Muros de quincha con un tejido de caña muy frágil, cubierta con un barro muy pobre por el poco tiempo de podrido.

Adobe de mala calidad por tener un barro poco trabajado y podrido. Así mismo el uso de la cascarilla de arroz en su elaboración no es adecuado dada su fragilidad y corto tamaño, restándole resistencia al bloque.

Techos bajos y sin ninguna inclinación, con lo cual hay poca ventilación y el agua de lluvias se acumula sobre ellos.

Muros, cada vez más delgados de quincha $o$ adobe.

Utilización de planchas de zinc para cubrir sus techos, lo cual soluciona temporalmente la impermeabilización, pero provoca intensos calentamientos de los ambientes.

No ejecución de cimientos cuando se trabaja los muros de adobe.

Por lo expuesto, el sistema constructivo a base de barro no es obsoleto, pero requiere constantemente renovarse para plantear una arquitectura que enfrente los nuevos usos y problemas climatológicos. 


\section{La actividad turística y la protección del patrimonio rural}

Es importante indicar que algunos hechos relacionados con el turismo han provocado una reflexión hacia la revalorización de la arouitectura rural por parte de sus pobladores.

En el año 1991, en Túcume se construyó un museo de sitio inspirado en las construcciones ruraies, lo cual tuvo una gran aceptación del visitante sensible a estas formas y tecnologías. Pero en el poblador local esto causó desconcierto, porque ellos esperaban un edificio de ladrillos y concreto con formas urbanas y modernas; pero al escuchar los halagos de los visitantes y el que este edificio se hizo acreedor a un premio del Colegio de Arquitectos del Perú, replantean su raciocinio y actualmente se encuentran en un proceso de revalorización de la tecnología heredada, conjuntamente con arqueólogos, arquitectos y constructores, que sí creen que se puede hacer arquitectura moderna con adobe $y$ quincha. A esto se agrega el hecho de que actualmente se viene ejecutando en Túcume un programa de Turismo Sostenible en el cual algunas acciones apuntan a mejorar la vivienda para dar alojamiento al turista.

Finalmente y para que no se piense que la prédica expresada en este artículo no sólo está en el plano de las ideas, se presenta una obra donde participa la autora con un equipo de personas que creen en la tecnología y la tradición en la localidad rural de Nancolán en Túcume. Esta obra se refiere a una capilla para Nuestra Señora de la Natividad, actualmente en construcción, en la cual se ha intentado resumir las ideologías del poblador, inspirándose por un lado en el Templo del Adoratorio y por otro en una capilla cristiana. Es importante mencionar que se está construyendo con esfuerzo comunal, dirigido por el curandero de la zona, señor Víctor Bravo Chozo. (ver Dibujo 8)

\section{Dibujo 8}

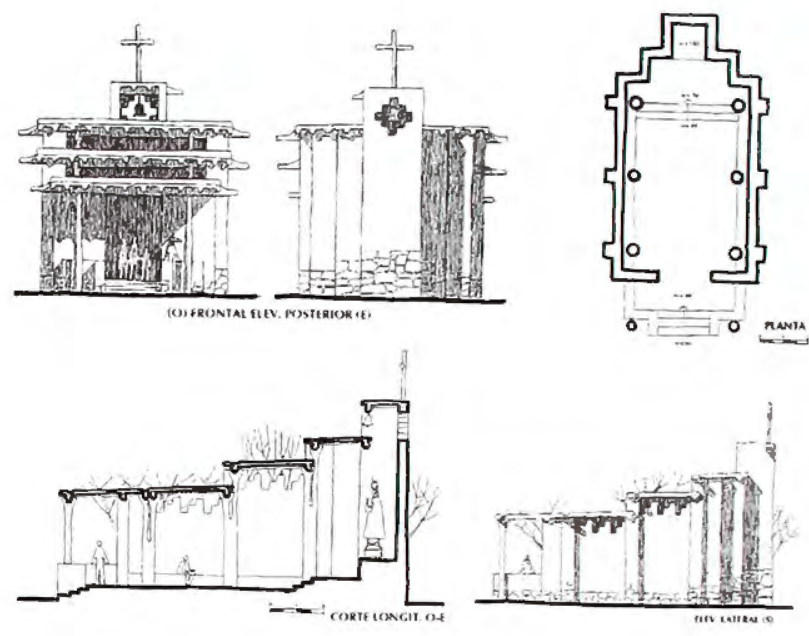

Algunas tareas

La revalorización de estas expresiones arquitectónicas populares pasa por dar algunos pasos claves que sería importante enfatizar a modo de cierre de este artículo:

Se debe identificar y estudiar los tipos arquitectónicos vernaculares de valor en todo el país, en un proceso que busca rescatar y difundir la identidad cultural de estas poblaciones.

Sería importante estructurar estos tipos destacados y los lugares de donde surgen en circuitos turísticos que complementen a los existentes. Incluso muchas de estas viviendas podrían refaccionarse para dar alojamiento al turista.

Revalorar estas expresiones populares requiere de campañas que deben comenzar por la población que vive en ellas, pues muchas veces está esperando el momento más adecuado para demolerlas y construir en su lugar una casa de material noble (de ladrillo y concreto armado).

Pero también entidades como el INC y Prom-Perú deben sensibilizarse y comprometerse en estas tareas. 
Otro campo donde se debe plantear la importancia de estas edificaciones y pueblos es la universidad, especialmente en las carreras de Turismo, Arquitectura, Ingeniería, Arqueología, entre otras.

\author{
Rosana Correa Álamo \\ Facultad Turismo \\ Universidad San Martín de Porres \\ Lima, Perú \\ jbrc@ correo.dnet.com.pe
}




\section{BIBLIOGRAFIA}

CAMPANA, CRISTOBAL.

1983 La Vivienda Mochica, Ed. Varese Editores, Trujillo-Perú.

CAMPANA, CRISTOBAL

1994 La Cultura Mochica, Concytec, LimaPerú.

HEYERDHAL THOR, SANDWEISS DANIEL, NARVAEZ ALFREDO

1994 Piramyds of Tucume.

MAKOWSKI HANULA KRYSZTOF

1994 "Las Grandes Culturas de la Costa Norte" en Historia y Cultura del Perú, Eds. Fernando Silva-Santisteban y Marco Curatola, Universidad de Lima, Museo de la Nación y Banco de Crédito. 